Check for updates

Cite this: RSC Adv., 2018, 8, 27796

Received 12th April 2018

Accepted 7th July 2018

DOI: 10.1039/c8ra03140a

rsc.li/rsc-advances

\title{
Aquatic photodegradation of clofibric acid under simulated sunlight irradiation: kinetics and mechanism analysis $\dagger$
}

\author{
Xiangdan Zhang, (D) *a Zongchao Liu, ${ }^{\text {a }}$ Qingqing Kong, ${ }^{\mathrm{b}}$ Guoguang Liu, (D) ${ }^{\mathrm{a}}$ \\ Wenying $\mathrm{Lv}{ }^{a}$ Fuhua $\mathrm{Li}^{\mathrm{a}}$ and Xiaoxuan $\mathrm{Lin}^{\mathrm{a}}$
}

\begin{abstract}
Clofibric acid is one of the most frequently detected pharmaceuticals in various aquatic environments. Photodegradation of clofibric acid in water under simulated sunlight was investigated. The effects of different initial concentrations, $\mathrm{pH}$ conditions and dissolved oxygen were examined. Photodegradation of clofibric acid followed a pseudo-first-order kinetics model, and the rate decreased gradually with the increasing initial concentration of clofibric acid. Dissolved oxygen inhibited the photodegradation of clofibric acid. As a result of varying reaction species of clofibric acid, the initial $\mathrm{pH}$ conditions greatly influenced its photodegradation. Quenching experiments showed that the self-sensitization process via . $\mathrm{OH}$ and ${ }^{1} \mathrm{O}_{2}$ occured during photodegradation of clofibric acid, and the bimolecular reaction rate constants of clofibric acid with $\cdot \mathrm{OH}$ and ${ }^{1} \mathrm{O}_{2}$ were determined via the competition kinetics method to be $3.93( \pm 0.20) \times 10^{8}$ and $2.38( \pm 0.12) \times 10^{6} \mathrm{~L} \mathrm{~mol}^{-1} \mathrm{~s}^{-1}$, respectively. In addition, the transformation products of clofibric acid were identified by the UPLC-Q-TOF-MS microsystem, and eight products were detected. It is proposed that the photodegradation of clofibric acid occurred mainly via decarboxylation, dechlorination, $\cdot \mathrm{OH}$ addition and ${ }^{1} \mathrm{O}_{2}$ attack reaction.
\end{abstract}

\section{Introduction}

In recent years, pharmaceuticals and personal care products (PPCPs) have emerged as a novel class of pollutants due to their incomplete degradation in sewage treatment plants. ${ }^{1}$ A large number of studies have investigated the presence, fate, and behaviour of PPCPs in aquatic environments. ${ }^{2-6}$

Clofibric acid (2-(4-chlorophenoxy)-2-methylpropionic acid, CA) is one common type of PPCP. It is an active metabolite of clofibrate, etofyllin clofibrate and etofibrate with therapeutic doses of about 1-2 $\mathrm{g} \mathrm{d}^{-1}$ per person. ${ }^{7,8}$ Nowadays, many patients are suffering from angiocardiopathy problems, and an increasing number of blood lipid regulators are being consumed year by year. ${ }^{9}$ However, drugs ingested by humans cannot be fully utilized, and more than $60 \%$ is excreted via urine or faeces; thus, these species ultimately end up in sewage treatment plants. ${ }^{10}$ Furthermore, several previous investigations have demonstrated that CA cannot be effectively eliminated in conventional sewage treatment plants. ${ }^{11,12}$ Ever since CA was

${ }^{a}$ School of Environmental Science and Engineering, Guangdong University of Technology, Guangzhou Higher Education Mega Center, No. 100 Waihuan Xi Road, Panyu District, Guangzhou 510006, China.E-mail: zhangxiangdan@hotmail.com ${ }^{b}$ School of Environmental Science and Engineering, Sun Yat-Sen University, Guangzhou 510275, China

† Electronic supplementary information (ESI) available. See DOI: 10.1039/c8ra03140a first identified in wastewater in the USA in the 1970s, it has been frequently detected in many STP effluents, ${ }^{\mathbf{1 0}}$ surface water, ${ }^{\mathbf{1 3}}$ and even drinking water. ${ }^{14}$ Its concentrations have been measured up to $13.5 \mathrm{ng} \mathrm{L^{-1 }}, 46.4 \mathrm{ng} \mathrm{\textrm {L } ^ { - 1 }}$ and $50.6 \mathrm{ng} \mathrm{L}^{-1}$ in the Yellow River, Haihe River and the lower reaches of the Dongjiang River, respectively, in China. ${ }^{13}$ It has been reported that CA can affect the reproductive axis of fish. ${ }^{15}$ Thus, once CA is released into the environment, it is very necessary to consider its fate, degradation pathways, persistence, and impact on the aquatic environment.

As a result of the absorption of light energy, many types of pollutants can be reduced in an aquatic environment. ${ }^{16-20}$ Pharmaceuticals are expected to be susceptible to direct photodegradation, where the direct absorption of photons leads to degradation of pollutants or indirect photolysis, which occurs in the presence of photosensitisers. ${ }^{21,22}$ In addition, researchers have shown that reactive oxygen species (ROS) including singlet oxygen $\left({ }^{1} \mathrm{O}_{2}\right)$ and even stronger oxidant hydroxyl radical $(\cdot \mathrm{OH})$ can be photogenerated by certain drugs to subsequently oxidize and degrade the pollutants, which is designated as the selfsensitized photodegradation of pollutants. ${ }^{23-27}$

To date, research on CA has primarily focused on its removal by AOPs, ${ }^{7,28-32}$ adsorption, ${ }^{33-37}$ catalytic technology, ${ }^{38-40}$ or joint processes, ${ }^{41}$ and studies on the behavior of CA in the environment are still very limited. However, these technologies may have some drawbacks; for example, AOPs may induce high energy consumption of the UV lamp and the generation of more 
toxic products. ${ }^{42,43}$ Adsorption cannot completely remove contaminants from the environment, and the catalytic process may introduce new chemicals into the water, which may cause new problems.

According to Jennifer L. Packer, ${ }^{44}$ photolysis is one of the important processes affecting the behavior of CA in the environment. Therefore, it is necessary to offer detailed information about the photodegradation of CA to better evaluate its potential risks.

This study aims to explore the degradation kinetics and mechanism of CA under simulated sunlight and to identify the main degradation products during CA photodegradation. The effect of oxygen concentration on the photodegradation of CA was investigated by gas purging experiments. The mechanisms of CA photolysis were explored by quenching experiments, and the bimolecular reaction rate constant was determined through the competitive dynamics method. The major photolysis products were identified with ultra-performance liquid chromatography/mass spectrometry, which enabled the analysis of possible photolysis pathways. Finally, the effects of water matrices and constituents on the degradation of CA were evaluated. The results will help elucidate the fate and behavior of $\mathrm{CA}$, thus contributing to the evaluation of its environmental risks.

\section{Materials and methods}

\subsection{Materials}

CA $(>97 \%)$ and sorbic acid were purchased from TCI Reagent Co. Ltd. (Shanghai, China). HPLC-grade reagents (acetonitrile, methanol, etc.) were obtained from Shanghai ANPEL Scientific Instrument Co. Ltd. (Shanghai, China). Benzoic acid (99.5\%) and sodium azide (99\%) were purchased from Aladdin Industrial Corporation (Shanghai, China), and furfuryl alcohol (FFA) (99\%) was purchased from the Sigma-Aldrich Company. Acetic acid (99\%), isopropanol (99.7\%), humic acid, $\mathrm{NaOH}, \mathrm{H}_{2} \mathrm{SO}_{4}$, $\mathrm{MgSO}_{4}, \mathrm{ZnSO}_{4}, \mathrm{CuSO}_{4}, \mathrm{Fe}_{2}\left(\mathrm{SO}_{4}\right)_{3}, \mathrm{NaCl}, \mathrm{NaNO}_{3}, \mathrm{NaHCO}_{3}$ and $\mathrm{KH}_{2} \mathrm{PO}_{4}$ were obtained from Chengdu Kelong Chemical Reagent Co. Ltd. (Sichuan, China). All reagents were of analytical grade and were used without further purification. Ultrapure water (resistance $>18.2 \mathrm{M} \Omega$ ) was produced by a water purification system (TKA, Germany).

\subsection{Experimental methods}

2.2.1 Photodegradation of CA. Photodegradation experiments were carried out using a sunlight simulator (XPA-7, Aanjing XUJ, Co. Ltd) with a hollow cylindrical quartz tube photoreactor. An $800 \mathrm{~W}$ xenon lamp placed in a double-walled quartz cooling jacket was selected as the simulated sunlight source. The emission spectrum of the xenon lamp and sunlight is shown in Fig. $\mathrm{S} 1 . \dagger$ The reaction liquid consisting of $5 \mathrm{mg} \mathrm{\textrm {L } ^ { - 1 }}$ CA was placed into a $50 \mathrm{ml}$ quartz tube, and this solution was stirred by a magnetic stirrer during the experiments. The temperature was controlled at $25 \pm 1{ }^{\circ} \mathrm{C}$ using a constanttemperature liquid-circulating apparatus, and the $\mathrm{pH}$ of the solution was controlled at $7( \pm 0.1)$ by adjusting with $0.1 \% \mathrm{NaOH}$ and $0.1 \% \quad \mathrm{H}_{2} \mathrm{SO}_{4}$ beforehand. During all experiments, maximum 6 irradiated samples $(2 \mathrm{ml}$ each) were withdrawn from the photoreactor using pipettes every $5 \mathrm{~min}$. After filtration by a $0.45 \mu \mathrm{m}$ PES membrane, the samples were analyzed by the reversed-phase high-performance liquid chromatography system.

2.2.2 Determination of bimolecular reaction rate constants and steady-state concentration. To study the sensitivity of the CA reaction with $\cdot \mathrm{OH}$ or ${ }^{1} \mathrm{O}_{2}$, the bimolecular rate constant was determined by the competition kinetics method (eqn (1) and (2)). Benzoic acid (BA), with a known rate constant $\left(k \cdot{ }_{\mathrm{OH}, \mathrm{BA}}=5.9\right.$ $\left.\times 10^{9} \mathrm{~mol}^{-1} \mathrm{~s}^{-1}\right),{ }^{45}$ and furfuryl alcohol (FFA) $\left(k^{1} \mathrm{O}_{2}, \mathrm{FFA}=8.3 \times\right.$ $10^{7}$ ) were used as reference compounds in this study. ${ }^{46} \mathrm{~A}$ solution of BA or FFA was photolyzed along with solutions containing CA. Aliquots were removed at various time points and analyzed by HPLC.

$$
\begin{array}{r}
\ln \left(\frac{[\mathrm{CA}]_{t}}{[\mathrm{CA}]_{0}}\right)=\frac{k \cdot \mathrm{OH}, \mathrm{CA}}{k \cdot \mathrm{OH}, \mathrm{BA}} \ln \left(\frac{[\mathrm{BA}]_{t}}{[\mathrm{BA}]_{0}}\right) \\
\ln \left(\frac{[\mathrm{CA}]_{t}}{[\mathrm{CA}]_{0}}\right)=\frac{k_{\mathrm{I}} \mathrm{O}_{2}, \mathrm{CA}}{k_{\mathrm{O}_{2}, \mathrm{FFA}}} \ln \left(\frac{[\mathrm{FFA}]_{t}}{[\mathrm{FFA}]_{0}}\right)
\end{array}
$$

here, $[\mathrm{CA}],[\mathrm{BA}]$ and $[\mathrm{FFA}]$ are the concentrations of $\mathrm{CA}, \mathrm{BA}$ and FFA; $k$. OH,CA and $k^{1} \mathrm{O}_{2}$, CA are the bimolecular reaction rate constants of $\cdot \mathrm{OH}$ and ${ }^{1} \mathrm{O}_{2}$ with $\mathrm{CA}$.

The steady-state concentrations of $\cdot \mathrm{OH}$ and ${ }^{1} \mathrm{O}_{2}$ were determined by the loss of BA and FFA according to eqn (3) to (6): ${ }^{77,48}$

$$
\begin{gathered}
\mathrm{BA}+\cdot \mathrm{OH} \rightarrow \text { intermediates } \\
-\mathrm{d}[\mathrm{BA}] / \mathrm{d} t=k \cdot \mathrm{OH}, \mathrm{BA}[\cdot \mathrm{OH}]_{\mathrm{ss}}[\mathrm{BA}]=k_{\mathrm{obs}, \mathrm{BA}}[\mathrm{BA}] \\
\mathrm{FFA}+{ }^{1} \mathrm{O}_{2} \rightarrow \text { intermediates } \\
-\mathrm{d}[\mathrm{FFA}] / \mathrm{d} t=k^{1} \mathrm{O}_{2}, \mathrm{FFA}\left[{ }^{1} \mathrm{O}_{2}\right]_{\mathrm{ss}}[\mathrm{FFA}]=k_{\mathrm{obs}, \mathrm{FFA}}[\mathrm{FFA}]
\end{gathered}
$$

here, $[\cdot \mathrm{OH}]_{\mathrm{ss}}$ and $\left[{ }^{1} \mathrm{O}_{2}\right]_{\mathrm{ss}}$ are the steady-state concentrations of - $\mathrm{OH}$ and ${ }^{1} \mathrm{O}_{2} ; k_{\mathrm{obs}, \mathrm{BA}}$ and $k_{\mathrm{obs}, \mathrm{FFA}}$ are the degradation rates of [BA] and [FFA].

2.2.3 Analytical method. Concentrations were analyzed by HPLC equipped with a photodiode array detector and a Zorbax Eclipse XDB-C18 $(2.1 \times 150 \mathrm{~mm}, 5 \mu \mathrm{m})$ column. The temperature of the column was set at $35{ }^{\circ} \mathrm{C}$, the injection volume was set at $4 \mu \mathrm{l}$, and the velocity of the mobile phase was controlled at 0.2 $\mathrm{ml} \mathrm{min}{ }^{-1}$. CA concentrations were detected at a wavelength of $219 \mathrm{~nm}$ using $55: 45$ methanol-acetonitrile mixed solution ( $1: 1,0.1 \%$ acetic acid) and buffered aqueous solution of

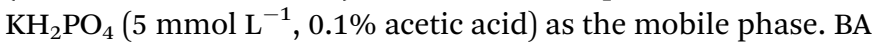
concentrations were detected at $228 \mathrm{~nm}$ using $20: 80$ acetonitrile and buffered aqueous solution of $\mathrm{KH}_{2} \mathrm{PO}_{4}\left(10 \mathrm{mmol} \mathrm{L}{ }^{-1}\right)$ as the mobile phase. FFA concentrations were detected at $219 \mathrm{~nm}$ using 50 : 50 methanol and $0.2 \%$ acetic acid aqueous solution as the mobile phase.

The intermediate products were investigated through the UPLC-Q-TOF-MS microsystem (Thermo Fisher). Beforehand, the sample was prepared by conducting the photodegradation of CA $\left(5 \mathrm{mg} \mathrm{L}^{-1}\right)$ for $30 \mathrm{~min}$; then, the solution was concentrated 
ten times in a rotary evaporator (RE-5299, YU HUA INSTR UMENT, China), and the concentrated solution was transferred to a sample vial for detection. The instrument used for sample testing was equipped with a Hypersil GOLD-C18 column $(50 \times$ $2.1 \mathrm{~mm}, 1.9 \mu \mathrm{m})$. UPLC method: sample volume: $4 \mu \mathrm{L}$; mobile phase: A (0.1\% FA water), B (methanol); 0-2 min: $98 \%$ A, 2$16 \mathrm{~min}$ : $98 \%$ A transferred to $5 \% \mathrm{~A}, 16-18 \mathrm{~min}: 5 \% \mathrm{~A}, 18.1-$

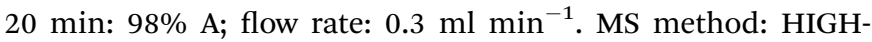
FLOW.mstune; sheath gas flow rate: 30; aux gas flow rate: 10; sweep gas flow rate: 0 ; spray voltage (IKVI): 3.5 ; capillary temp $\left({ }^{\circ} \mathrm{C}\right)$ : 320; aux gas heater temp $\left({ }^{\circ} \mathrm{C}\right): 350$.

\section{Results and discussion}

\subsection{Effect of different initial concentrations on CA photodegradation}

Fig. 1 shows that $67-80 \%$ of CA degraded in the samples under simulated sunlight irradiation, whereas the dark control experiment revealed almost no decay of CA, which suggested that the photochemical reaction is an important process in removing CA. Photodegradation of $\mathrm{CA}$ at different initial concentrations was consistent with a pseudo-first-order kinetics model, and the photolysis rate could be influenced by the initial concentration. As the initial concentration of CA increased from $1 \mathrm{mg} \mathrm{L}{ }^{-1}$ to $7 \mathrm{mg} \mathrm{L}^{-1}$ at $\mathrm{pH}$ of $7( \pm 0.1)$, the photolysis rate gradually decreased from $0.0532( \pm 0.0027) \mathrm{min}^{-1}$ to $0.0377( \pm 0.0019) \mathrm{min}^{-1}$. Correlation analysis showed that the degradation rate constant was negatively correlated $\left(R^{2}=\right.$ $0.9987)$ with $\ln \left(C_{0}\right)$. This is because the photolysis rate is directly related to the number of photons that can be accepted by CA per unit time. The fewer the photons accepted by CA per unit time, the slower the degradation of CA.

\subsection{Effect of dissolved oxygen on CA photodegradation}

By using $\mathrm{N}_{2}$ or $\mathrm{O}_{2}$ as a purging gas, experiments were carried out to study the effect of dissolved oxygen on the photodegradation

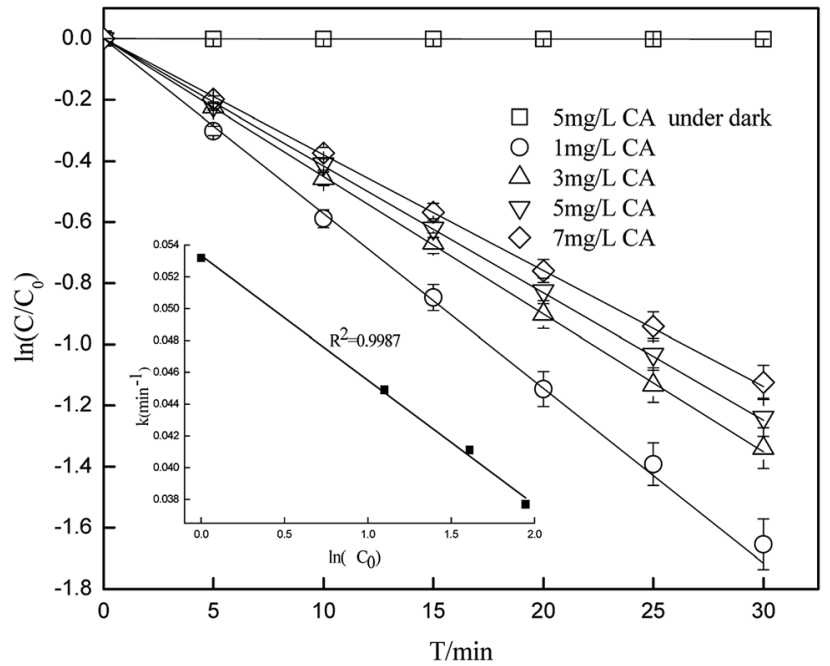

Fig. 1 Degradation of $C A$ at different initial concentrations $(\mathrm{pH}=$ $7( \pm 0.1))$.

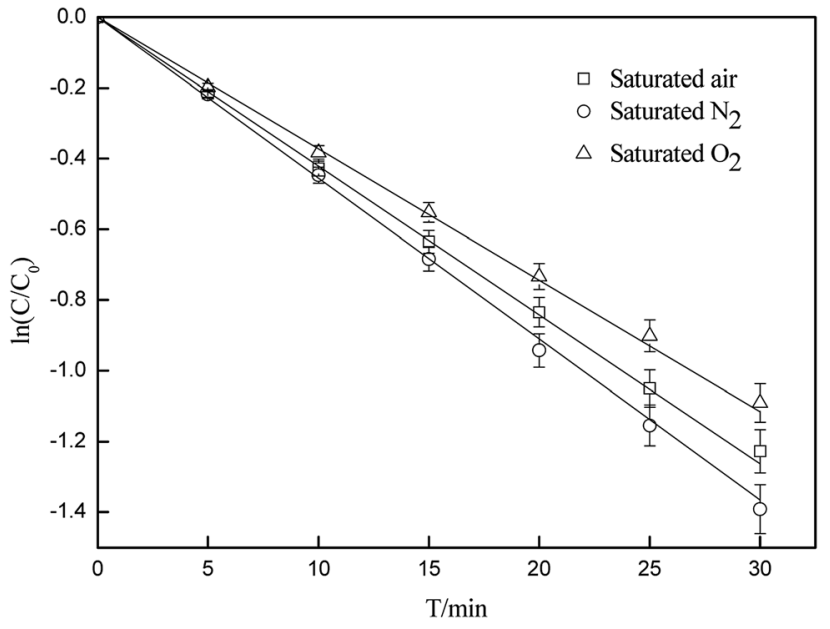

Fig. 2 Effects of oxygen concentration on the photodegradation of $\mathrm{CA}\left(C_{0}=5 \mathrm{mg} \mathrm{L}^{-1}, \mathrm{pH}=7( \pm 0.1)\right)$.

of CA. As illustrated in Fig. 2, the dissolved oxygen inhibited the photodegradation of $\mathrm{CA}$. The rate constants were $0.0431( \pm 0.0022) \quad \min ^{-1}, \quad 0.0386( \pm 0.0019) \min ^{-1}$ and $0.0411( \pm 0.0021) \mathrm{min}^{-1}$ in the absence and presence of $\mathrm{O}_{2}$, and under saturated air, respectively. Some research studies have also showed that most photochemical reactions occur at the excited states, whereas dissolved oxygen may quench the excited states via energy/electron transfer, which can lead to the formation of singlet oxygen. ${ }^{49}$ Quenching of the excited states may restrain the direct photodegradation process, whereas the formation of singlet oxygen can promote the indirect process. Quenching experiments (below) demonstrated that ${ }^{1} \mathrm{O}_{2}$ can induce the degradation of CA through a self-sensitization process. This indicates that the presence of dissolved oxygen contributed to the inhibition of direct photodegradation of CA more than promotion through a self-sensitization process, and it also showed an overall inhibitory effect on CA photodegradation.

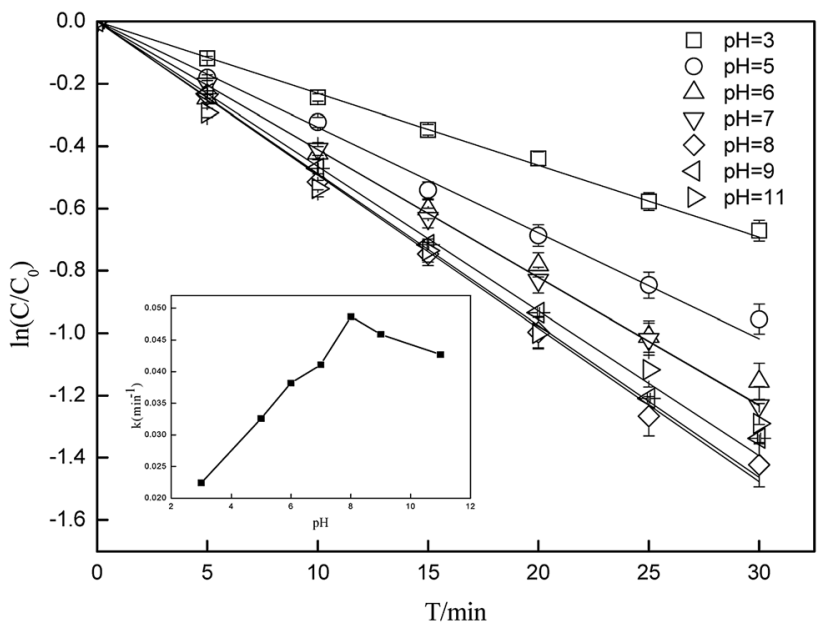

Fig. 3 Degradation of $\mathrm{CA}$ at different initial $\mathrm{pH}$ conditions $\left(C_{0}=\right.$ $5 \mathrm{mg} \mathrm{L}^{-1}$ ). 


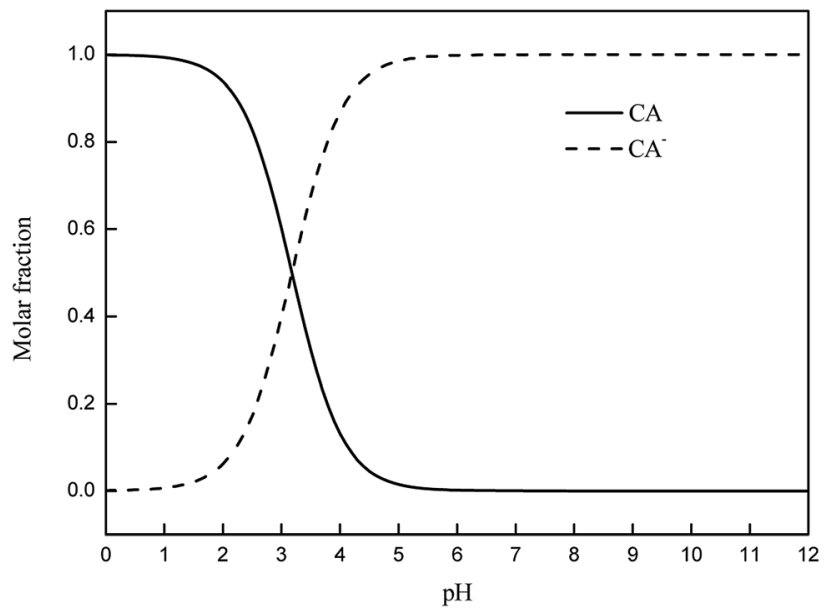

Fig. 4 Distribution of dissociation species of CA.

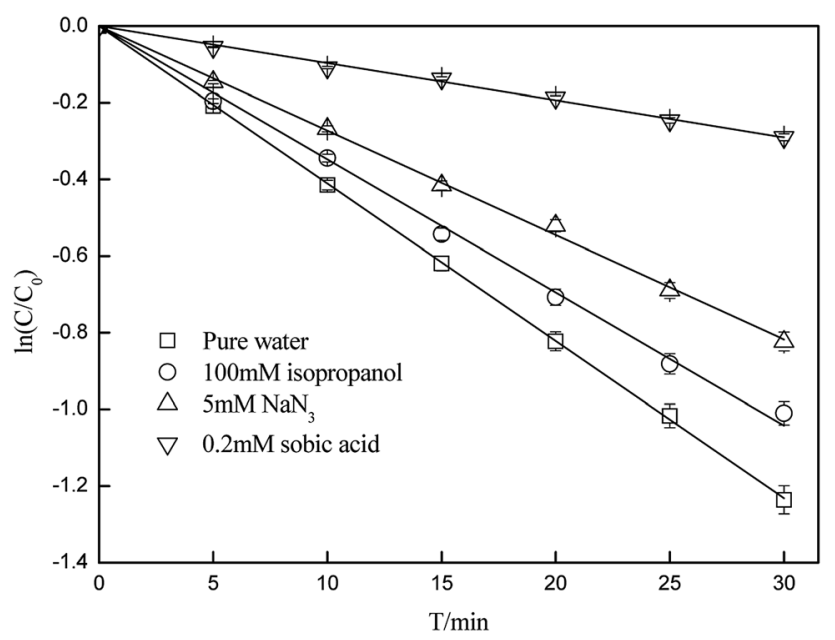

Fig. 5 Effects of isopropanol, $\mathrm{NaN}_{3}$ and sobic acid on the photodegradation of $\mathrm{CA}\left(C_{0}=5 \mathrm{mg} \mathrm{L}^{-1}, \mathrm{pH}=7( \pm 0.1)\right)$.

\subsection{Effect of different pH conditions on $\mathrm{CA}$ photodegradation}

Photolysis can be greatly influenced by $\mathrm{pH}$; thus, specific experiments were also performed to determine the rate constants of CA photolysis at different initial $\mathrm{pH}$ values. Fig. 3

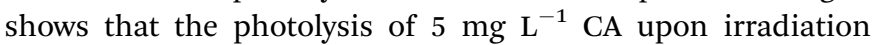
under simulated sunlight was distinctly dependent on the initial pH. From pH 3.0 to 8.0, the rate constants initially increased from $0.0227( \pm 0.0011) \mathrm{min}^{-1}$ to $0.0494( \pm 0.0025) \mathrm{min}^{-1}$ and subsequently decreased slightly from $\mathrm{pH} 8.0$ to 11.0. The considerable difference in the rate constants with varying initial $\mathrm{pH}$ might be due to the change in the reaction species of CA. The $\mathrm{p} K_{\mathrm{a}}$ value of CA was $3.18,{ }^{50}$ and its species distribution is shown in Fig. 4. The amount of the molecular form decreased, whereas the amount of the anionic form increased as the $\mathrm{pH}$ value increased from 3.0 to 11.0. Comparing $k_{\text {. } \mathrm{OH}, \mathrm{CA}}$ and $k^{1} \mathrm{O}_{2}$, $\mathrm{CA}$ at different $\mathrm{pH}$ conditions, it was observed that $k_{\cdot \mathrm{OH}, \mathrm{CA}}$ and $k^{1} \mathrm{O}_{2}$, CA increased gradually as $\mathrm{pH}$ increased from 3.0 to 8.0, whereas both decreased at $\mathrm{pH}=11.0$. Many researchers have also demonstrated that the substrate anion is more reactive than its neutral (or protonated) species because of the high electrical density on the ring system of the substrate anion, ${ }^{\mathbf{5 1 , 5 2}}$ which leads to accelerated degradation of pollutants as $\mathrm{pH}$ increases. Thus, the photodegradation of CA accelerates as the amount of the anionic form increases. Additionally, under alkaline conditions $(\mathrm{pH} 8-11), \cdot \mathrm{OH}$ might be scavenged by $\mathrm{HO}^{-}$(eqn (7)), ${ }^{32,53}$ which may impair the oxidization of $\mathrm{CA}$ by $\cdot \mathrm{OH}$; thus, the photodegradation of $\mathrm{CA}$ decreased slightly from $\mathrm{pH} 8.0$ to 11.0.

$$
\cdot \mathrm{OH}+\mathrm{HO}^{-} \rightarrow \mathrm{O}^{--}+\mathrm{H}_{2} \mathrm{O} k=1.2 \times 10^{10} \mathrm{M}^{-1} \mathrm{~s}^{-1}
$$

\subsection{Analysis of the mechanism of CA photodegradation}

Quenching experiments were used to explore the mechanisms of CA photolysis. Fig. 5 demonstrates that the addition of isopropanol (the $\cdot \mathrm{OH}$ quencher), ${ }^{45,54} \mathrm{NaN}_{3}$ (the ${ }^{1} \mathrm{O}_{2}$ and $\cdot \mathrm{OH}$ quencher), ${ }^{\mathbf{4 5}, 54,55}$ and sobic acid (the triplet excited state quencher $)^{54,56}$ to the reaction solution had clear inhibiting effect on CA photodegradation, which indicated that both $\cdot \mathrm{OH}$ and ${ }^{1} \mathrm{O}_{2}$ were generated and played roles in CA photodegradation. The photolysis rates of $\mathrm{CA}$ with the quenchers were $0.0348( \pm 0.0017)$ (isopropanol), $0.0273( \pm 0.0014)\left(\mathrm{NaN}_{3}\right)$ and $0.0097( \pm 0.0005)$ (sobic acid) $\mathrm{min}^{-1}$. Based on existing research, we can estimate the contributions of $\cdot \mathrm{OH},{ }^{1} \mathrm{O}_{2}$, and the triplet excited state to the overall photodegradation of CA as follows:

$$
\begin{gathered}
R \cdot \mathrm{OH} \\
k \\
R_{{ }^{\mathrm{O}_{2}}} \\
k
\end{gathered}
$$

here, $R_{\text {. }}{ }_{\mathrm{OH}}, R^{1} \mathrm{O}_{2}$, and $R_{\mathrm{CA}^{*}}$ are the contribution rates of photodegradation via $\cdot \mathrm{OH},{ }^{1} \mathrm{O}_{2}$, and the triplet excited state of $\mathrm{CA}$, respectively; $k_{\cdot \mathrm{OH}}, k^{{ }_{1} \mathrm{O}_{2}}$ and $k_{\mathrm{CA}^{*}}$ are the rate constants of photodegradation via $\cdot \mathrm{OH},{ }^{1} \mathrm{O}_{2}$, and the triplet excited state of CA, respectively; $k_{\text {isopropanol, }} k_{\mathrm{NaN}_{3}}$, and $k_{\text {sobic }}$ acid are the rate constants for the addition of isopropanol $(100 \mathrm{mM}),{ }^{57}$ sodium

Table 1 The bimolecular rate constants $\left(k_{\cdot} \mathrm{OH}, \mathrm{BA}\right.$ and $\left.k^{1} \mathrm{O}_{2^{\prime}} \mathrm{CA}\right)$ for the reaction between $\mathrm{CA}$ and ROS in various solutions

\begin{tabular}{lllll}
\hline & Pure water & $\mathrm{pH}=3$ & $\mathrm{pH}=5$ & $\mathrm{pH}=8$ \\
\hline$k \cdot \mathrm{OH}, \mathrm{BA} \times 10^{-8}\left(\mathrm{~L} \mathrm{~mol}^{-1} \mathrm{~s}^{-1}\right)$ & $3.93( \pm 0.20)$ & $2.49( \pm 0.12)$ & $3.48( \pm 0.17)$ & $4.37( \pm 0.22)$ \\
$k{ }^{1} \mathrm{O}_{2}, \mathrm{CA} \times 10^{-6}\left(\mathrm{~L} \mathrm{~mol}^{-1} \mathrm{~s}^{-1}\right)$ & $2.38( \pm 0.12)$ & $0.11( \pm 0.01)$ & $1.90( \pm 0.10)$ & $3.22( \pm 0.16)$
\end{tabular}




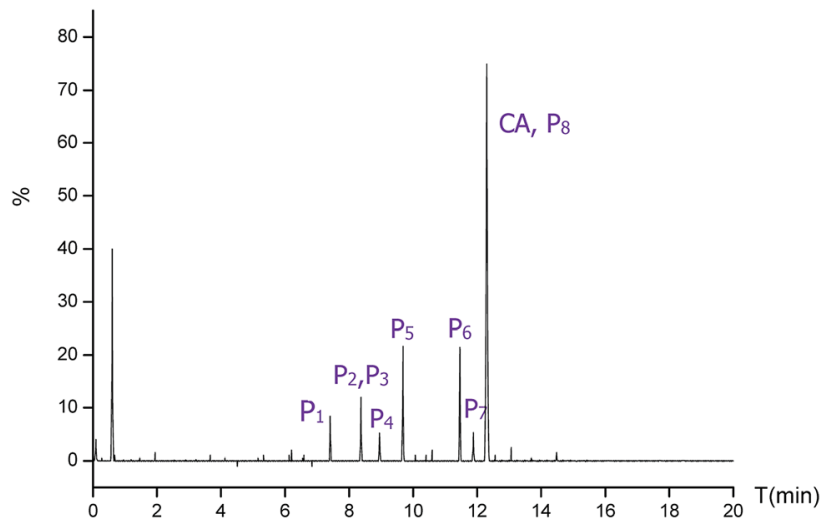

Fig. 6 The total ion chromatogram of CA photodegradation.

azide $(5 \mathrm{mM}){ }^{58}$ and sobic acid $(0.2 \mathrm{mM})$ into reaction solutions; ${ }^{59} k$ is the rate constant of the photodegradation of CA alone.
The calculations showed that $\cdot \mathrm{OH},{ }^{1} \mathrm{O}_{2}$, and $\mathrm{CA}^{*}$ account for $15.37( \pm 0.77) \%, \quad 18.25( \pm 0.91) \%$ and $58.15( \pm 2.91) \%$, respectively, of the total photodegradation of CA, which means that a self-sensitization process via $\cdot \mathrm{OH}$ and ${ }^{1} \mathrm{O}_{2}$ existed during photodegradation of CA, whereas direct photolysis was prevalent in pure water. Moreover, to study the sensitivity of the CA reaction with. $\mathrm{OH}$ and ${ }^{1} \mathrm{O}_{2}$, the bimolecular reaction rate constants of CA with $\cdot \mathrm{OH}$ and ${ }^{1} \mathrm{O}_{2}$ were determined by selecting BA and FFA as probes. As we can see from Table $1, k \cdot$ OH,CA and $k^{\mathrm{A}_{2}}, \mathrm{CA}$ are 3.93 $( \pm 0.20) \times 10^{8}$ and $2.38( \pm 0.12) \times 10^{6} \mathrm{~L} \mathrm{~mol}^{-1} \mathrm{~s}^{-1}$ in pure water; using eqn (6)-(9), the steady-state concentrations of $\cdot \mathrm{OH}$ and ${ }^{1} \mathrm{O}_{2}$ were calculated to be $4.24( \pm 0.21) \times 10^{-11}$ and $2.03( \pm 0.1) \times 10^{-11} \mathrm{~mol} \mathrm{~L}^{-1}$, respectively.

To further elucidate the mechanism of CA photodegradation, the solutions irradiated for $30 \mathrm{~min}$ were analyzed by the UPLC-Q-TOF-MS microsystem, and eight main products of CA degradation were detected. The total ion chromatograms are shown in Fig. 6; the fragment chart of the secondary ion mass spectra of $\mathrm{P}_{1}-\mathrm{P}_{8}$ is shown in Fig. $\mathrm{S} 2, \dagger$ and the relevant mass spectrometry information and proposed structure are

Table 2 Mass spectrometry information and the proposed structure of the photodegradation intermediates of CA

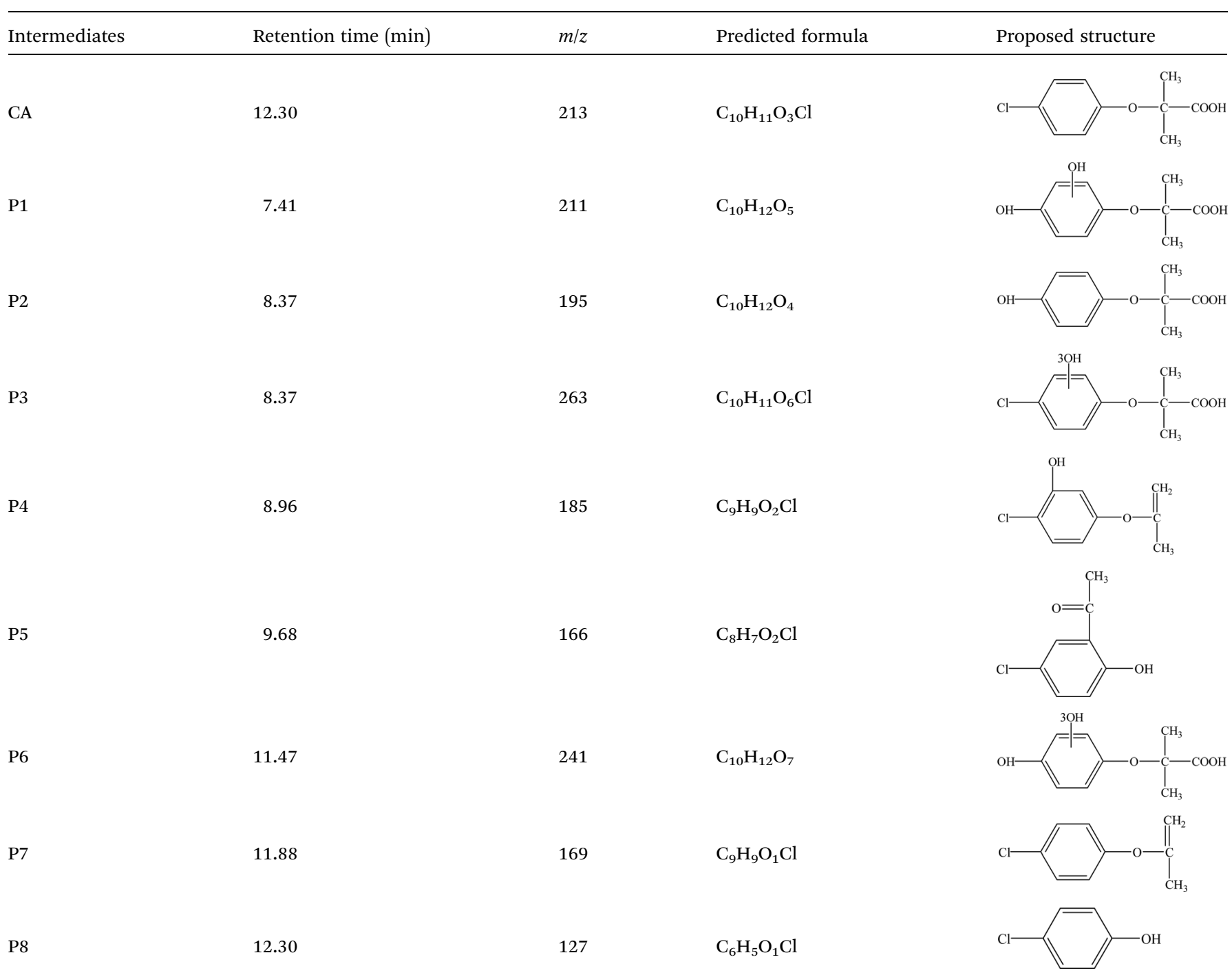


shown in Table 2. Based on structure identification of the photoproducts, a plausible photodegradation pathway scheme of CA consisting of several steps is proposed in Fig. 7.

It is presumed that Path $\mathrm{I}$ is the direct decomposition of CA under simulated sunlight, which produces product $\mathrm{P}_{7}$ through decarboxylation. Path II is due to aryloxy-carbon cleavage, that is, C4-O is broken into methacrylate and 4-chlorophenolate $\left(\mathrm{P}_{8}\right)$. This route has been reported in the degradation pathways of CA in the UV/chlorine process. ${ }^{60}$ 4-Chlorophenolate has also been detected during the photocatalytic and ozonation degradation of CA. ${ }^{61,62}$ Simultaneously, coexisting methacrylate and 4chlorophenolate may react with $\mathrm{P}_{5}$ through acylation reaction. Path III represents dechlorination and subsequent attack by - $\mathrm{OH}$ yielding 2-(4-hydroxyphenoxy)-isobutyric acid $\left(\mathrm{P}_{2}\right)$. Doll and Frimmel ${ }^{63}$ proposed the same pathway during their investigation of the catalytic photodegradation products of CA.

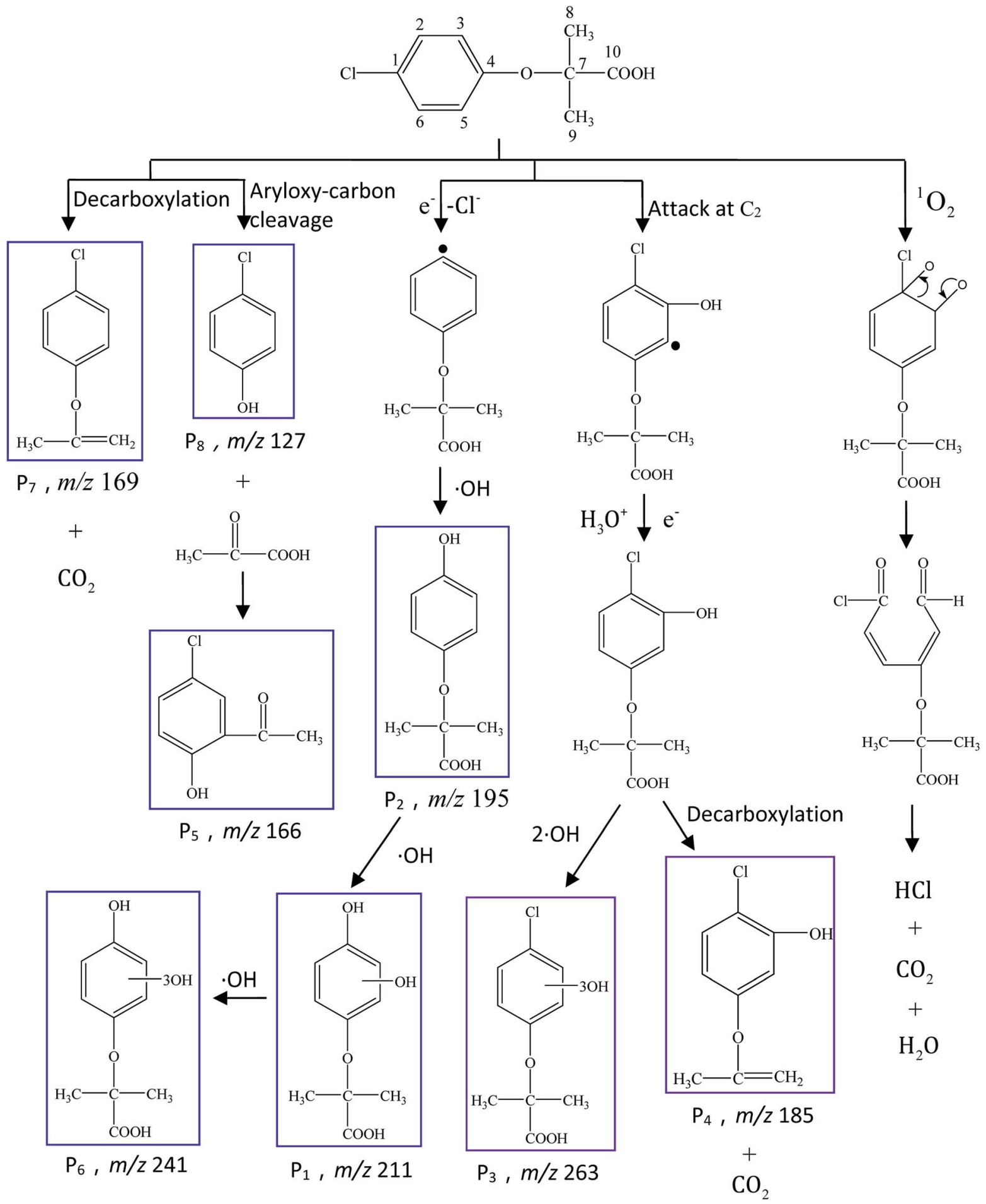

Fig. 7 Proposed photodegradation pathways of $C A$ under simulated sunlight irradiation in aqueous solution $\left(C_{0}=5 \mathrm{mg} \mathrm{L}^{-1}, \mathrm{pH}=7( \pm 0.1)\right)$. 


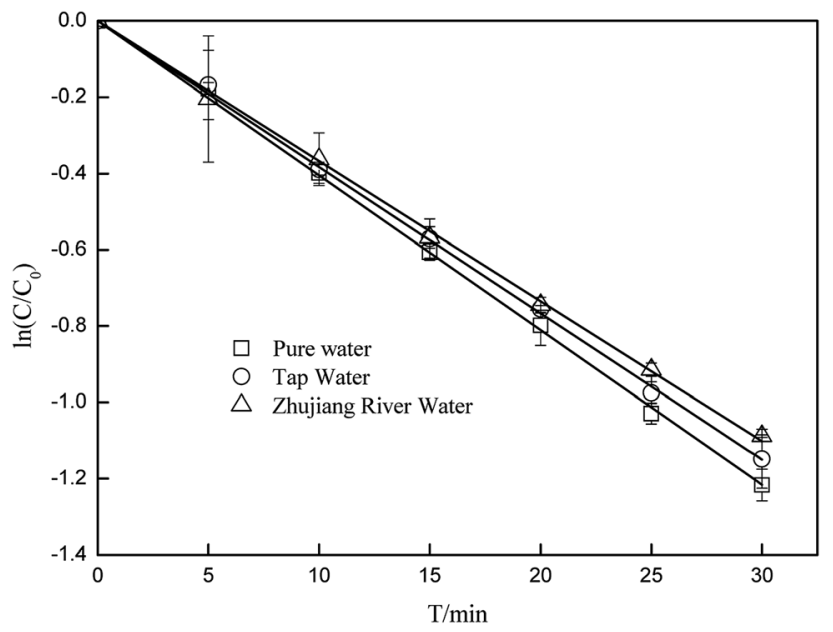

Fig. 8 The photodegradation of $C A$ in different water matrices $\left(C_{0}=\right.$ $5 \mathrm{mg} \mathrm{L}^{-1}$ ).

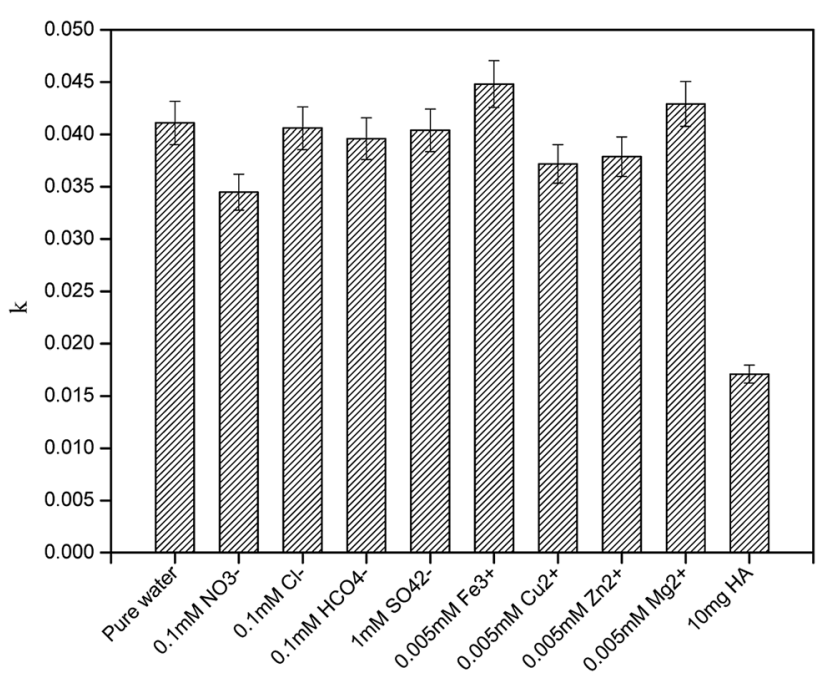

Fig. 9 Effects of humic acid $(\mathrm{HA})$ and some representative ions on the photodegradation of $C A$ in pure water $\left(C_{0}=5 \mathrm{mg} \mathrm{L}^{-1}, \mathrm{pH}=7( \pm 0.1)\right)$.

Continuously, under the action of $\cdot \mathrm{OH}, \mathrm{P}_{2}$ was converted to $\mathrm{P}_{1}$ and then $\mathrm{P}_{6}$. Path IV represents the electrophilic addition of $\cdot \mathrm{OH}$. $\cdot \mathrm{OH}$ attacks at $\mathrm{C} 2$ to form the mono-hydroxylation product 2-(4-chloro-3-hydroxy-phenoxy)-2-methyl-propionic acid, which was not determined in this study and then, the trichloro-hydroxylation product $\left(\mathrm{P}_{3}\right)$ was formed. Additionally, 2-(4-chloro-3-hydroxy-phenoxy)-2-methyl-propionic acid can change to $\mathrm{P}_{4}$ via decarboxylation. Path $\mathrm{V}$ is initiated by ${ }^{1} \mathrm{O}_{2}$ attack at the aromatic $\mathrm{C}$ atom with the ${ }^{1} \mathrm{O}_{2}$ /dioxetane mechanism. Chen ${ }^{62}$ has proposed this pathway in the photocatalytic degradation of CA by $\mathrm{g}-\mathrm{C}_{3} \mathrm{~N}_{4} / \mathrm{P}_{25}$ composites. Due to the endoperoxide cleavage, the aldehyde and acid chloride byproducts can be formed. Similar aldehyde and carboxylic acid formation processes have also been previously observed. ${ }^{64}$

Both self-sensitization and direct photolysis play significant roles during CA photodegradation under simulated sunlight irradiation, which is consistent with the results of quenching experiments.

\subsection{Effects of water matrices and constituents on the degradation of CA}

To better elucidate the photodegradation of CA under simulated sunlight in an aquatic environment, photodegradation of CA in different water matrices was carried out, and the effects of some constituents on the degradation of CA were evaluated. As seen in Fig. 8, the degradation of CA in tap water and Zhujiang River water (primary properties of the two water samples are listed in Table $\mathbf{S 1 \dagger}$ ) was inhibited slightly, which may be due to the effects of coexisting constituents. HA and some representative ions were selected; as shown in Fig. 9, even though $\mathrm{Fe}^{3+}$ and $\mathrm{Mg}^{2+}$ can promote CA photodegradation to some extent, $\mathrm{NO}^{3-}, \mathrm{Cu}^{2+}, \mathrm{Zn}^{2+}$, and $\mathrm{HCO}_{3}{ }^{-}$, especially $\mathrm{HA}$, could significantly inhibit photodegradation. In natural water matrices, high TOC and $\mathrm{UV}_{254}$ may be the main reasons for low CA degradation efficiencies.

\section{Conclusions}

The exploration of the mechanism and products of CA photodegradation under simulated sunlight irradiation is of great significance to assess its environmental fate and risks. The results showed that photodegradation of CA follows a pseudofirst-order kinetics model, and the photolysis rate decreased gradually as the initial concentration of CA increased. The presence of dissolved oxygen contributed to the inhibition of direct photodegradation of CA more than the promotion through a self-sensitization process, and it showed an overall inhibitory effect on CA photodegradation. Because the reaction species of CA varied with the change in $\mathrm{pH}$ of aqueous solutions, the rate constants of CA photodegradation changed accordingly. Quenching experiments indicated that a selfsensitization process via $\cdot \mathrm{OH}$ and ${ }^{1} \mathrm{O}_{2}$ existed during the photodegradation of $\mathrm{CA}$, whereas direct photolysis was the main part. The bimolecular reaction rate constants of clofibric acid with $\cdot \mathrm{OH}$ and ${ }^{1} \mathrm{O}_{2}$ were determined to be 3.93 $( \pm 0.20) \times 10^{8}$ and $2.38( \pm 0.12) \times 10^{6} \mathrm{~L} \mathrm{~mol}^{-1} \mathrm{~s}^{-1}$, respectively. Eight main photoproducts of CA were detected in this study, and they were proposed to be produced from decarboxylation, dechlorination, $\cdot \mathrm{OH}$ addition and ${ }^{1} \mathrm{O}_{2}$ attack reactions.

\section{Conflicts of interest}

There are no conflicts to declare.

\section{Acknowledgements}

This work is supported by the National Natural Science Foundation of China (No. 21377031 and 21677040) and the Science and Technology Planning Project of Guangdong Province (No. 2017A050506052). The authors would like to thank all the editors and reviewers for their help in improving this paper. 


\section{Notes and references}

1 N. Zhang, J. M. Li, G. G. Liu, X. L. Chen and K. Jiang, Mar. Pollut. Bull., 2017, 117, 386.

2 Q. Sun, Y. Li, M. Li, M. Ashfaq, M. Lv, H. Wang, A. Hu and C. P. Yu, Chemosphere, 2016, 150, 596.

3 E. N. Evgenidou, I. K. Konstantinou and D. A. Lambropoulou, Sci. Total Environ., 2015, 505, 905.

4 Y. L. Lin and B. K. Li, J. Taiwan Inst. Chem. Eng., 2015, 58, 318-323.

5 S. Mohapatra, C. H. Huang, S. Mukherji and L. P. Padhye, Chemosphere, 2016, 159, 526.

6 J. L. Wilkinson, P. S. Hooda, J. Swinden, J. Barker and S. Barton, Environ. Pollut., 2018, 234, 864.

7 M. Queropastor, C. Garridoperez, A. A. Merino and J. M. Q. Alonso, Ozone: Sci. Eng., 2016, 38, 425-433.

8 C. G. Daughton and T. A. Ternes, Environ. Health Perspect., 1999, 6(suppl. 107), 907.

9 L. Wenzhen, L. Shuguang, C. Nuo, G. Xiaogang, Q. Zhaofu, F. Ji and L. Kuangfei, Water Sci. Technol., 2009, 60, 29832989.

10 T. A. Ternes, Water Res., 1998, 32, 3245-3260.

11 S. Zorita, L. Mårtensson and L. Mathiasson, Sci. Total Environ., 2009, 407, 2760-2770.

12 C. Zwiener and F. H. Frimmel, Sci. Total Environ., 2003, 309, 201-211.

13 W. Li, G. G. Ying, J. L. Zhao, X. B. Yang, C. Feng, T. Ran, L. Shan and L. J. Zhou, Sci. Total Environ., 2010, 408, 3139.

14 K. Reddersen, T. Heberer and U. Dünnbier, Chemosphere, 2002, 49, 539-544.

15 T. J. Runnalls, D. N. Hala and J. P. Sumpter, Aquat. Toxicol., 2007, 84, 111.

16 E. Lee, H. K. Shon and J. Cho, J. Hazard. Mater., 2014, 276, 19.

17 K. Sornalingam, A. Mcdonagh and J. L. Zhou, Sci. Total Environ., 2016, 550, 209.

18 W. Huang, C. Jing, X. Zhang, M. Tang, L. Tang, M. Wu and N. Liu, Chem. Eng. J., 2018, 349, 603-612.

19 N. Liu, W. Huang, X. Zhang, L. Tang, L. Wang, Y. Wang and M. Wu, Appl. Catal., B, 2017, 221, 119-128.

20 W. Huang, N. Liu, X. Zhang, M. Wu and L. Tang, Appl. Surf. Sci., 2017, 425, 107-116.

21 R. Nassar, A. Trivella, S. Mokh, M. Al-Iskandarani, H. Budzinski and P. Mazellier, J. Photochem. Photobiol., A, 2016, 336, 176-182.

22 Y. Li, Y. Pan, L. Lian, S. Yan, W. Song and Y. Xin, Water Res., 2017, 109, 266-273.

23 D. Ma, G. Liu, W. Lv, K. Yao, X. Zhang and H. Xiao, Environ. Sci. Pollut. Res., 2014, 21, 7797-7804.

24 N. Agrawal, R. S. Ray, M. Farooq, A. B. Pant and R. K. Hans, Photochem. Photobiol., 2007, 83, 1226-1236.

25 Y. Chen, C. Hu, J. Qu and M. Yang, J. Photochem. Photobiol., A, 2008, 197, 81-87.

26 D. Ren, B. Huang, D. Xiong, H. He, X. Meng and X. Pan, J. Environ. Sci., 2016, 54, 196-205.
27 D. Ren, B. Huang, D. Xiong, H. He, X. Meng and X. Pan, J. Environ. Sci., 2017, 54, 196-205.

28 S. S. Sable, P. P. Ghute, P. Álvarez, F. J. Beltrán, F. Medina and S. Contreras, Catal. Today, 2015, 240, 46-54.

29 H. Lin, J. Wu and H. Zhang, Chem. Eng. J., 2014, 244, 514521.

30 S. S. Sable, F. Medina and S. Contreras, Appl. Catal., B, 2014, 150-151(suppl.), 30-36.

31 X. Kong, Z. Wu, Z. Ren, K. Guo, S. Hou, Z. Hua, X. Li and J. Fang, Water Res., 2018, 137, 242-250.

32 X. Lu, Y. Shao, N. Gao, J. Chen, H. Deng, W. Chu, N. An and F. Peng, Chem. Eng. J., 2017, 331, 364-371.

33 C. M. Dai, J. Zhang, Y. L. Zhang, X. F. Zhou, Y. P. Duan and S. G. Liu, Environ. Sci. Pollut. Res., 2013, 20, 5492.

34 Y. L. Zhang, Y. J. Liu, C. M. Dai, X. F. Zhou and S. G. Liu, Water, Air, Soil Pollut., 2014, 225, 2064.

35 Z. Hasan, E. J. Choi and S. H. Jhung, Chem. Eng. J., 2013, 219, 537-544.

36 A. S. Mestre, A. Nabiço, P. L. Figueiredo, M. L. Pinto, M. S. C. S. Santos and I. M. Fonseca, Chem. Eng. J., 2016, 286, 538-548.

37 A. Gil, N. Taoufik, A. M. García and S. A. Korili, Environ. Technol., 2018, 1-40.

38 S. Li, Y. Tang, W. Chen, H. Zhe, X. Li and L. Li, J. Colloid Interface Sci., 2017, 504, 238.

39 S. S. Sable, P. P. Ghute, D. Fakhrnasova, R. B. Mane, C. V. Rode, F. Medina and S. Contreras, Appl. Catal., B, 2017, 209, 523-529.

40 H. Lin, X. Zhong, C. Ciotonea, X. Fan, X. Mao, Y. Li, B. Deng, H. Zhang and S. Royer, Appl. Catal., B, 2018, 230, 1-10.

41 Y. Gao, G. Yu, K. Liu, S. Deng, B. Wang, J. Huang and Y. Wang, Chem. Eng. J., 2017, 330, 157-165.

42 Y. Gao, N. Gao, W. Chu, Q. Yang and D. Yin, RSC Adv., 2017, 7, 33627-33634.

43 Y. Zhu, M. Wu, N. Gao, W. Chu, K. Li and S. Chen, Chem. Eng. J., 2018, 335, 520-529.

44 J. L. Packer, J. J. Werner, D. E. Latch, K. Mcneill and W. A. Arnold, Aquat. Sci., 2003, 65, 342-351.

45 Y. Ji, L. Zhou, Y. Zhang, C. Ferronato, M. Brigante, G. Mailhot, X. Yang and J. M. Chovelon, Water Res., 2013, 47, 5865-5875.

46 D. E. Latch, B. L. Stender, J. L. Packer, W. A. Arnold and K. Mcneill, Environ. Sci. Technol., 2003, 37, 3342-3350.

47 Y. H. Guan, J. Ma, X. C. Li, J. Y. Fang and L. W. Chen, Environ. Sci. Technol., 2011, 45, 9308.

48 A. L. Boreen, W. A. Arnold and K. Mcneill, Environ. Sci. Technol., 2005, 39, 3630-3638.

49 W. Xue, J. Chen and Q. Xie, J. Hazard. Mater., 2016, 307, 344. 50 W. Z. Li, S. G. Lu, N. Chen, X. G. Gu, Z. F. Qiu, F. Ji and K. F. Lin, Water Sci. Technol., 2009, 60, 2983.

51 Z. Chen, G. Cao and Q. Song, Environ. Chem. Lett., 2010, 8, 33-37.

52 L. Mao, C. Meng, C. Zeng, Y. Ji, X. Yang and S. Gao, Sci. Total Environ., 2011, 409, 5376-5381.

53 G. V. Buxton, C. L. Greenstock, W. P. Helman and A. B. Ross, J. Phys. Chem. Ref. Data, 2009, 17, 513-886. 
54 C. Liang, H. Zhao, M. Deng, X. Quan, S. Chen and H. Wang, J. Environ. Sci., 2015, 27, 115.

55 G. Miolo, G. Viola, D. Vedaldi, F. Dall'Acqua, A. Fravolini, O. Tabarrini and V. Cecchetti, Toxicol In Vitro, 2002, 16, 683-693.

56 A. C. Velosa, W. J. Baader, C. V. Stevani, C. M. Mano and E. J. Bechara, Chem. Res. Toxicol., 2007, 20, 1162-1169.

57 P. Chen, W. Lv, Z. Chen, J. Ma, R. Li, K. Yao, G. Liu and F. Li, Environ. Sci. Pollut. Res. Int., 2015, 22, 12585-12596.

58 P. Chen, F. L. Wang, K. Yao, J. S. Ma, F. H. Li, W. Y. Lv and G. G. Liu, Bull. Environ. Contam. Toxicol., 2016, 96, 203-209.
59 J. Ma, W. Lv, C. Ping, Y. Lu, F. Wang, F. Li, K. Yao and G. Liu, Environ. Sci. Pollut. Res., 2016, 23, 14294-14306.

60 Y. Tang, X. Shi, Y. Liu, L. Feng and L. Zhang, R. Soc. Open Sci., 2018, 5, 171372.

61 R. Rosal, M. S. Gonzalo, K. Boltes, P. Letón, J. J. Vaquero and E. Garcíacalvo, J. Hazard. Mater., 2009, 172, 1061-1068.

62 P. Chen, F. Wang, Q. Zhang, Y. Su, L. Shen, K. Yao, Z. F. Chen, Y. Liu, Z. Cai and W. Lv, Chemosphere, 2017, $172,193$.

63 T. E. Doll and F. H. Frimmel, Water Res., 2004, 38, 955-964. 64 R. Rosal, M. S. Gonzalo, K. Boltes, P. Letón, J. J. Vaquero and E. García-Calvo, J. Hazard. Mater., 2009, 172, 1061-1068. 